\title{
Intellectual capital management paradigm for Malaysian SMEs in Kuching, Sarawak
}

\author{
Dr Muhammad Khalique \\ Senior Lecturer, Department of Business Management \\ Faculty of Economics and Business \\ Universiti Malaysia Sarawak, Kuching, Sarawak, Malaysia \\ Email: drmkhalique@gmail.com
}

\author{
Prof. Dr Abu Hassan bin Md. Isa \\ Head, Department of Accounting and Finance \\ Faculty of Economics and Business, \\ Universiti Malaysia Sarawak, Kuching, Sarawak, Malaysia
}

\author{
Dr Jamal Abdul Nassir Bin Shaari \\ Senior Lecture, Department of Business Management, \\ Faculty of Economics and Business \\ Universiti Malaysia Sarawak, Kuching, Sarawak, Malaysia
}

\begin{abstract}
Previous studies rarely examined the role of intellectual capital in SMEs in Malaysia. In addition, most studies neglect the SMEs operating in Kuching, Sarawak. The main crux of this paper is to explore the role of intellectual capital management as an integral element of electronics organizations in Kuching, Sarawak, Malaysia. Intellectual capital management plays a critical role for the development and sustainable of small and medium enterprises. In the beginning of the twenty first century, intellectual capital management attained significant attention from academicians, researchers and practitioners. Therefore, it is indispensible to examine the role of intellectual capital in SMEs.
\end{abstract}

Keywords- Intellectual capital; human capital; customer capital; technological capital; spiritual capital

\section{INTRODUCTION}

In modern age, knowledge is considered as a power. In past it was a notion that knowledge and brainpower supersede tangible assets as the main source of competitive advantage is now commonly accepted in the management domain [1-3]. The present economy namely knowledge based economy is mainly based on intangible assets such as intellect, skill and expertise. Knowledge appears as the most important ingredient for the success and sustainability of organizations. In other words we can say that knowledge-based assets are appeared as the life blood of organizations, particularly hightech or knowledge intensive organizations. In a new economy, knowledge management is becoming the most important challenge for strategy implementation in organizations[4]. Further they argued that the identification and evaluation of intellectual capital is also one of the most important issues in knowledge management.

Intellectual capital management is recognized as the advanced form of knowledge management. For example, intellectual capital is based on knowledge and it is very useful for the long time success and competitive advantages of knowledge-based organizations [4]. Further, they argued that the importance of intellectual capital is widely recognized but it is difficult to identify it in organizations. Nowadays, determining and managing of intellectual capital has become a main objective in organizations in order to ascertain its value and gain in competitive advantage [5]. This main objective of this study is to identify the relationship of the intellectual with the performance of electronics organizations in Kuching, Sarawak, Malaysia.

\section{LITERATURE REVIEW}

From the past two decades intellectual capital (IC) has emerged as the most important construct within the strategic management [6]. The term intellectual was introduced by Jon Kenneth Galbraith in 1969 [7, 8]. The term "Intellectual Capital" collectively refers to all resources that determine the value of an organization, and the competitiveness of an enterprise [9]. Intellectual capital encompasses a large set of factors which are the main sources that help to generate competitive advantage in organizations both in the present and the future [5]. In addition, they argued that intellectual capital can be measured be establishing or identifying different components of intellectual capital in organization. The components of intellectual capital should be represented by suitable indicators that could be applied and compared to other organizations.

Intellectual capital is based on heterogeneous knowledgebased resources and it necessitate to split the intellectual capital into its component and then analyze each of them separately [4]. In intellectual capital filed many theoretical and empirical studies have been done in recent years. Researchers proposed different framework for classifying or identifying different components of intellectual capital, for example, a variety of intangibles compositions are currently proposed and employed. At the embryonic stage of the development of intellectual capital researchers such as [3, 10-13] agreed that intellectual capital is mainly based on two and three components namely human capital, customer capital or relational and structural capital. To understand the concept of intellectual capital in more depth [14] and [15] extend two more components namely social capital and technological capital. The spiritual capital is an integral part of intellectual capital [16]. [8] proposed an integrated intellectual capital 